\title{
IMPROVING ANTIBIOTIC PRESCRIBING PATTERN AND ASSESSMENT OF CO-MORBIDITIES ASSOCIATED WITH RESPIRATORY TRACT INFECTIONS
}

\author{
SHYAMA K. , PRUDENCE A. R. \\ Department of Pharmacy Practice, PSG College of Pharmacy, Coimbatore-641004, Tamil Nadu, India \\ Email: k.shyama21@gmail.com
}

Received: 01 Oct 2016 Revised and Accepted: 29 Dec 2016

\section{ABSTRACT}

Objective: The objective of this study was to describe the antibiotic prescribing pattern and co-morbidities associated with lower respiratory tract infections by means of cross-observational study.

Methods: A cross-sectional, open labelled and observational study was undertaken in a multi-speciality hospital for a period of 9 mo (November 2013-July2014). Lower respiratory tract infected patients who satisfied the selection criteria were included in the study. They were followed clinically and biochemically in the study.

Results: During the study period, most predominant antibiotics used were cephalosporin's which constitute about $63 \%$ (with $3^{\text {rd }}$ generation being the highest). Hypertension was found to be the most frequent co-morbidity (43\%). Route of administration for most of the patients was parenteral followed by tablets and a very few on capsules. A few were changed from parenteral to oral when they met with the clinical criteria's for switching over therapy.

Conclusion: This study describes the antibiotic prescribing pattern and co-morbidities associated with lower respiratory tract infected patients.

Keywords: Lower respiratory tract infection (LRTI), Antibiotics, Co-morbidities

(C) 2017 The Authors. Published by Innovare Academic Sciences Pvt Ltd. This is an open access article under the CC BY license (http://creativecommons.org/licenses/by/4. 0/) DOI: http://dx.doi.org/10.22159/ijpps.2017v9i2.15495

\section{INTRODUCTION}

Respiratory tract infections are the most common condition of patients hospital visit. A thorough study of antibiotic prescribing can help in suggesting modifications necessary for prescribing habits among physicians. National health science recommends certain guidelines for antibiotic prescription in patients with respiratory tract infections. These strategies include either no or delayed antibiotics prescribing and immediate antibiotics prescribing depending upon the clinical conditions of patients [1]. Appropriate information about organisms isolated and their sensitivity pattern is essential for choosing suitable antibiotics among multiple antibiotics available [2]. Proper prescribing pattern and adherence to standard guidelines can help antibiotic use rational and cost effective. Irrational prescription of antibiotics also leads to bacterial resistance [14]. This cross-observational study was done to evaluate the antibiotic prescribing pattern and co-morbidities associated with lower respiratory tract infections.

Pneumonia is considered to be the most common LRTI in hospitalised patients. The mortality rate associated with pneumonia is also high despite the use of antibiotics [3]. In 2000, Pneumonia and Influenza were the seventh leading cause of death in the U. S. WHO estimates 3-5 million worldwide cases of influenza annually $[3,4]$

The three main diagnostic criteria's for LRTI [5]:

- Firstly to evaluate the symptoms of patients to assess whether it is an infectious or noninfectious disorder.

- Secondly to consider which part of the respiratory tract is affected.

- Thirdly to find out the nature of the microorganism involved.

The World Health Organization (WHO) recommends the lesser use of injections can reduce the cost and pain for patients. Hence, a higher rate of parenteral prescriptions and lowest rate of the early switch over to oral antibiotic therapy is a matter of concern. In this context, the present study was designed to assess the antibiotic prescribing pattern followed by physicians in cases of patients diagnosed with LRTI. The various diagnostic tests conducted to evaluate the type of LRTI and their reliability in choosing appropriate antibiotics was also assessed. Co-morbidities associated with LRTI which caused a major health threat in the treatment of patients were also studied.

\section{MATERIALS AND METHODS}

A cross-sectional, observational, open labelled study was undertaken in a multi-speciality hospital for a period of 9 mo (November 2013-July 2014). A prospective study was done from February 2014 to July 2014 in the inpatient departments of general medicine, pulmonology and respiratory medicine. 93 patients diagnosed with lower respiratory tract associated diseases were included to study the antibiotic prescribing patterns and comorbidities (73 males, 20 females, with mean+SD age 58.51 \pm 12.173 ). They were followed clinically and biochemically before and after the initiation of antibiotic therapy for evidence of patient prognosis. Demographic details such as age, gender, history of smoking and alcohol consumption, co-morbidities, symptoms, laboratory investigations, sputum analysis, sensitivity patterns of organisms isolated from respiratory tract infections, procalcitonin level, arterial blood gases, pleural fluid analysis, chest radiographs were monitored and documented. Antibiotic therapy including the route of administration, dose, dosage, generic name, pharmacological class, and switch over therapy and also the outcomes of therapy was also monitored.

\section{Study approval}

The study proposal with the investigation protocol and the required documents was submitted to the Institutional Human Ethics Committee of the study site. The proposal with the Proposal No.14/041 was approved by the committee.

\section{Patient selection}

Inclusion criteria:

- Age: $>18 \mathrm{y}$.

- Gender: male and female.

- Patients with lower respiratory tract infections. 
- Patients prescribed with both narrow and broad spectrum antibiotics.

- Patients whose specimens were collected for culture tests.

\section{Exclusion Criteria:}

- Outpatients.

- ICU patients.

- Pregnant and nursing women.

- TB patients.

- Patients with autoimmune and sexually transmitted diseases.

\section{Statistical analysis}

Statistical analysis was done for the entire patients enrolled in the study. Statistical Package for Social Sciences (SPSS version 20) for Windows was used for analysis of data. Mean+SD and frequencies were used to express data. Patient's demographics were summarised using frequency and percentage tables. Baseline characteristics of entire patients were summarised using mean and standard deviation.

\section{Parameters for evaluation}

The parameters followed in the study includes gender distribution, the average age range of patients, social and family history, type of infection, average number of drugs per prescription, average number of antibiotics per prescription, the number of comorbidities per patient and diagnostic tests used.

\section{RESULTS}

\section{Gender and age}

Among 100 patients, 73 were males, and 20 were females. More patients enrolled in the study were male $(78 \%) n=73$ than female patients $(22 \%) n=20$. The majority of patients were under the age group of $50-70(75 \%) n=70$ compared to other age groups. According to age, $(18 \%) n=17$ patients were under the age group of $30-49$ and $(7 \%) n=6$ were under the age group of $20-29$ (table 1) [6].

\section{Social and family history}

Among 93 patients, (39\%) $n=36$ were having a significant family history of hypertension, thyroid disorders and type-2 diabetes mellitus. (43\%) $n=40$ patients were alcoholic and (57\%) $n=53$ were non-alcoholic (table 1). (55\%) $n=51$ were smokers and $(45 \%) n=42$ were non-smokers (table 1) [6].

Table 1: Patient demographic details $(\mathrm{N}=93)$

\begin{tabular}{|c|c|c|}
\hline Characteristics & Number & Percentage (\%) \\
\hline \multicolumn{3}{|l|}{ Gender } \\
\hline Male & 73 & 78 \\
\hline Female & 20 & 22 \\
\hline \multicolumn{3}{|l|}{ Age } \\
\hline $20-29$ & 6 & 7 \\
\hline $30-49$ & 17 & 18 \\
\hline $50-70$ & 70 & 75 \\
\hline Family history & 36 & 39 \\
\hline \multicolumn{3}{|l|}{ Social history } \\
\hline Alcoholic & 40 & 43 \\
\hline Non alcoholic & 53 & 57 \\
\hline Smoker & 51 & 55 \\
\hline Non smoker & 42 & 45 \\
\hline
\end{tabular}

\section{Symptoms}

Among 93 patients, most common symptoms experienced were breathlessness $(80 \%) n=74$, cough $(93 \%) n=84$, in which $(91 \%)$ $n=85$ were productive, fever $(34 \%) n=32$ and $(21 \%) n=20$ chest pain According to Modified Medical Research Council (MMRC) grade of breathlessness (17\%) $n=16$ were of $2,(14 \%) n=13$ of $2-3,(35 \%)$ $n=33$ of $3,(11 \%) n=10$ of $3-4$ and $(3 \%) n=3$ were 4 and $(20 \%) n=19$ had no breathlessness. (table 2) [6, 7].

\section{Diagnostic tests}

Among 93 patients, common diagnostic tests conducted were sputum test $(45 \%) n=42$. In that $(24 \%) n=22$ showed growth of microorganism. Procalcitonin level $(84 \%) n=78$ in which $(14 \%) n=13$ were elevated and other tests done were chest x-rays $(70 \%) n=65$, pleural fluid analysis (24\%) n=22and arterial blood gas (23\%) n=21 (fig. 1) [7].

\section{Table 2: Common symptoms experienced by patients}

\begin{tabular}{ll}
\hline Symptoms & Percentage (\%) \\
\hline Breathlessness & 80 \\
Cough & 93 \\
Productive & 91 \\
Fever & 34 \\
Chest pain & 21 \\
MMRC grade of breathlessness & \\
2 & 17 \\
$2-3$ & 14 \\
3 & 35 \\
$3-4$ & 11 \\
4 & 3 \\
No breathlessness & 20 \\
\hline
\end{tabular}

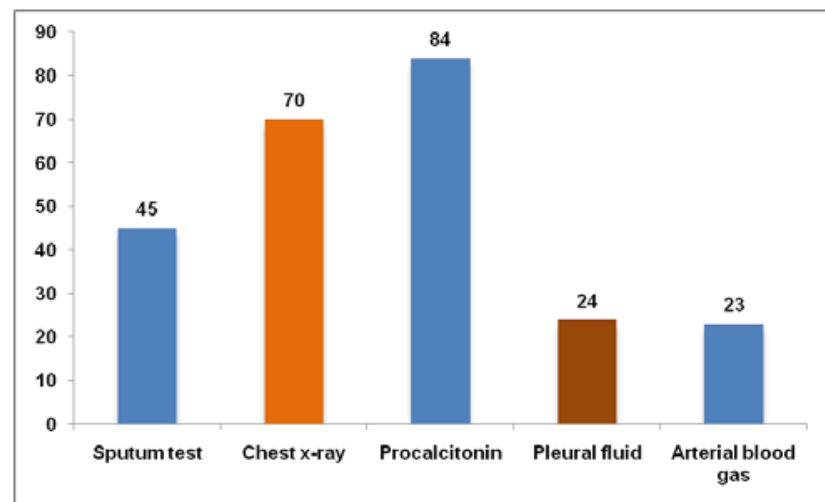

Fig. 1: Diagnostic tests $(\mathrm{N}=93)$

According to co-morbid conditions, (43\%) $n=25$ patients were having hypertension, (35\%) $n=21$ with diabetes mellitus (DM), (6\%) $n=4$ patients had thyroid disorders, $(5 \%) n=3$ with gastric disorders, $(18 \%) \mathrm{n}=11$ of patients had cardiovascular diseases (CVD) and $(25 \%) n=15$ with other diseases (table 3$)$.

Among 93 patients, (60\%) n=56 were on monotherapy, (32\%) $n=30$ on dual therapy and $(8 \%) n=7$ on triple therapy. Among 93 patients, $(55 \%) n=51$ were placed on empirical therapy and $(45 \%)$ $n=42$ on specific therapy. Out of 93 medication charts, $(64 \%) n=60$ contained generic name and (36\%) $n=33$ contained brand name (table 4) [6]. 
Table 3: Percentage of co-morbid conditions

\begin{tabular}{ll}
\hline Co-morbidities & Percentage (\%) \\
\hline Hypertension & 43 \\
Diabetes mellitus & 35 \\
Thyroid disorders & 6 \\
Gastric disorders & 5 \\
Heart diseases & 18 \\
Others & 25 \\
\hline
\end{tabular}

\section{Antibiotic prescribing process}

Table 4: Type of therapy $(\mathrm{N}=93)$

\begin{tabular}{ll}
\hline Number of antibiotics & Percentage (\%) \\
\hline Monotherapy & 60 \\
Dual therapy & 32 \\
Triple therapy & 8 \\
Empirical therapy & 55 \\
Specific therapy & 45 \\
Generic name & 64 \\
Brand name & 36 \\
\hline
\end{tabular}

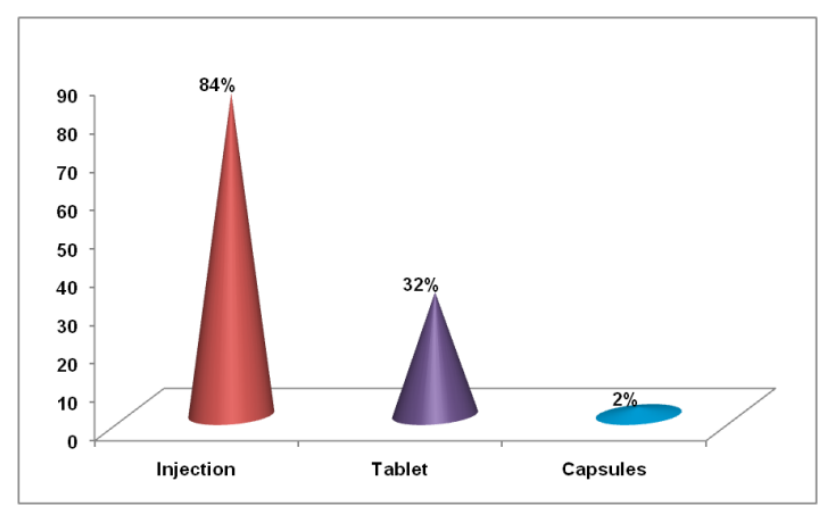

Fig. 2: Type of dosage prescribed $(\mathrm{N}=93)$

Among 93 patients, $(84 \%) n=78$ were on injections, $(32 \%) n=30$ on tablets and ( $2 \%) n=2$ on capsules (fig. 2 ).

Among 93 patients, there was a changeover of antibiotics within $72 \mathrm{~h}$ for $(18.27 \%) n=17$ patients and $(7.53 \%) n=7$ in $48 \mathrm{~h}$ after admission. $(5.3 \%)$ $\mathrm{n}=5$ were switched on from injections to tablets (table 5) [6-8].

Table 5: Changeover of antibiotics ( $N=93)$

\begin{tabular}{ll}
\hline Time & Percentage (\%) \\
\hline $48 \mathrm{~h}$ & 7.53 \\
$72 \mathrm{~h}$ & 18.27 \\
Switch over from injections to tablets & 5.3 \\
\hline
\end{tabular}

\section{Prescribing pattern of antibiotics}

Among 93 patients, most predominant class of antibiotic were cephalosporins $(63 \%) n=59$, fluroquinolones $(31 \%) n=29$, macrolides $(16 \%) n=15$, carbapenems $(12 \%) n=11$, penicillins $(16 \%) n=15$, aminoglycosides $(4 \%) n=4$ and tetracycline $(1 \%) n=1$ (table 6) $[7,9]$.

Table 6: Class of antibiotics

\begin{tabular}{ll}
\hline Class of antibiotic & Percentage (\%) \\
\hline Cephalosporins & 63 \\
Fluoroquinolones & 31 \\
Macrolides & 16 \\
Carbapenems & 12 \\
Penicillins & 16 \\
Aminoglycosides & 4 \\
Tetracycline & 1 \\
\hline
\end{tabular}

\section{Name of antibiotics}

Among 93 patients, higher rate of prescription were of ceftriaxone (49\%) $\mathrm{n}=46$, levofloxacin (26\%) $\mathrm{n}=24$,cefoperazone $\quad(12 \%)$ $\mathrm{n}=13$,azithromycin $(15 \%) \quad \mathrm{n}=14$, piperacillin $(16 \%) \quad \mathrm{n}=15$, meropenem $(10 \%) n=9$, imipenem $(2 \%) n=2$, metronidazole $(3 \%)$ $\mathrm{n}=3$, ofloxacin $(2 \%) \mathrm{n}=2$, amikacin $(3 \%) \mathrm{n}=3$,ciprofloxacin $(3 \%) \mathrm{n}=3$, vancomycin $(1 \%) \quad n=1$,rifampin $(1 \%) \quad n=1$,streptomycin $(1 \%)$ $\mathrm{n}=1$,clarithromycin $(1 \%) \mathrm{n}=1$,cefuroxime $(1 \%) \mathrm{n}=1$, doxycycline $(1 \%) n=1$ (table 7) $[6,9,13]$.

Table 7: Name of antibiotics prescribed

\begin{tabular}{ll}
\hline Name of antibiotics & Percentage \\
\hline Ceftriaxone & 49 \\
Levofloxacin & 26 \\
Cefoperazone & 12 \\
Azithromycin & 15 \\
Piperacillin+tazobactam & 16 \\
Meropenem & 10 \\
Imipenem & 2 \\
Metronidazole & 3 \\
Ofloxacin & 2 \\
Amikacin & 3 \\
Ciprofloxacin & 3 \\
Vancomycin & 1 \\
Streptomycin & 1 \\
Clarithromycin & 1 \\
Cefuroxime & 1 \\
Cefpodoxime & 1 \\
Doxycycline & 1 \\
\hline
\end{tabular}

\section{DISCUSSION}

The present study was intended to describe the antibiotic prescription pattern and co-morbidities in respiratory tract infected inpatients. Demographic characteristics indicate most of the patients were males with mean age 58.51 $\pm(12.173)$. Most common symptoms experienced by patients were a cough and breathlessness which is same as reported by Warren J. Mclsaac in his study [7]. For people who have experienced breathlessness, most of them showed MMRC grade 3. Out of 93 patients, $40 \% n=37$ of patients were alcoholics and $51 \% n=47$ were smokers. About $63 \% n=59$ of the patients had co-morbidities among which; the most predominant one was hypertension. Disease conditions were treated with antibiotics included LRTIs, pneumonia, exacerbation of COPD and asthma, bronchiectasis, etc. $86 \%$ of them had multiple diagnoses. Most common diagnostic tests conducted were procalcitonin level, sputum analysis, arterial blood gases and chest x-rays. Common drugs prescribed other than antibiotics included bronchodilators $(89 \%) n=83$ and steroids $(43 \%) n=40$. The mean duration of hospital stay for patients was $5 \pm 1.4 \mathrm{~d}$. Mean number of drugs per prescription was $7.76 \pm 1.31$.

In this study, most of the patients (93\%) $n=93$ admitted were treated with an antibiotic which was identified in many other studies. The most predominant antibiotics used were cephalosporin's $(63 \%) n=59$ ( $3^{\text {rd }}$ generation highest), followed by fluoro-quinolones $(31 \%) \mathrm{n}=29$, macrolides and then penicillins which were similar to the findings of G. Mazzaglia et. al [11]. In contradiction to the above-mentioned observation, Warren J. Mclsaac et. al reported that the most common antibiotics used were macrolides, followed by aminopenicillins, then cephalosporins and quinolones [7]. Third generation fluoro-quinolones, levofloxacin, macrolide antibiotic azithromycin and penicillins antibiotic piperacillin in combination with $\beta$-lactamase inhibitors were also widely used. Empirical therapy was given for 55\% $n=51$ and $45 \%$ $\mathrm{n}=42$ on specific therapy. Route of administration for most of the patient was parenteral same as that observed by Ravi Pathiyil Shankar et al., followed by tablets and a very few on capsules [12]. A few were changed from parenteral to oral when they met the clinical criteria's for switching over therapy. A changeover of antibiotics was observed within $48 \mathrm{~h}$ for $(8 \%) \mathrm{n}=7$ and $(18 \%) \mathrm{n}=17 \mathrm{in} 72 \mathrm{~h}$. 


\section{Limitations}

This study was performed on a limited number of patients affected with respiratory tract infections for a limited period of time. Also, sensitivity pattern of only certain pathogens affecting respiratory tract was evaluated. To arrive at an evidence-based conclusion, multicentre studies with a large population are required, taking into consideration all the factors responsible for increasing rate of antibiotic prescription and emerging resistance of microorganisms.

\section{CONCLUSION}

The study concluded that all the patients who visited with respiratory tract disease were prescribed with antibiotics and the most predominant comorbidity was hypertension. Cephalosporin's constituted the major proportion with the third generation being the highest and then fluoroquinolones. Route of administration was mostly parental. WHO recommends the lesser use of injections can reduce cost and pain for patients. Hence the higher rate of parenteral prescriptions and lowest rate of the early switch over to oral antibiotic therapy is a matter of concern.

\section{CONFLICTS OF INTERESTS}

Declared none

\section{REFERENCES}

1. NICE clinical guideline 69-respiratory tract infectionsantibiotic prescribing; 2008.

2. Christopher AE, Casimir N, Richard O. Microbiology of lower respiratory tract infections in Benin City, Nigeria. Malays J Med Sci 2011;18:27-31.

3. Anette $\mathrm{H}$, Joergen $\mathrm{N}$, Lene $\mathrm{AB}$. Aetiology and prediction of pneumonia in lower respiratory tract infection in primary care. Br J Gen Pract 2007;57:547-57.

4. Macfarlane J, Holmes W, Gard P, Macfarlane R, Rose D, Weston $\mathrm{V}$, et al. Prospective study of the incidence, aetiology and outcome of adult lower respiratory tract illness in the community. Thorax 2001;56:109-14.
5. Woodhead M, Blasi F, Ewig S, Huchon G, Leven M, Ortqvist A, et $a l$. Guidelines for the management of adult lower respiratory tract infections. Eur Respir J 2005;6:1138-80.

6. Abhishek PS, Usha G, Saumya D. Monitor the use of antibiotics in intensive care units with a special focus on restricted antibiotics in tertiary care hospital of India. Asian J Pharm Clin Res 2016;9:256-9.

7. Warren JM, Teresa TO. Antibiotics for lower respiratory tract infections: still too frequently prescribed? Can Fam Physician 2004;50:569-75.

8. Dilip N. Sequential switch therapy for lower respiratory tract infections. Chest 1998;113:211-8.

9. Hanmant A, Priyadarshini KOP. Prescription analysis to evaluate the rational use of antimicrobials. Int J Pharm Biol Sci 2011;2:315-9.

10. Brieman RF, Butler JC, Tenover FC, Elliott JA, Facklam RR. The emergence of drug-resistant pneumococcal infections in the United States. JAMA 1994;271:1831-5.

11. Mazzaglia G, Arcoraci V, Greco S, Cucinotta G, Cazzola M, Caputi AP. Prescribing habits of general practitioners in choosing an empirical antibiotic regimen for lower respiratory tract infections in adult in sicily. Pharmacol Res 1999;40:47-52.

12. Ravi PS, Praveen P, Nagesh KS, Joshy ME, Kottallur NB. Prescribing patterns of antibiotics and sensitivity patterns of common microorganisms in the internal medicine ward of a teaching hospital in Western Nepal: a prospective study. Ann Clin Microbiol Antimicrob 2003;2:2-7.

13. Arcojit G, Asoke KD, Prasanta KG, Sampurna P. An observational study of drug use in upper respiratory tract infection in patients attending ent outpatient department in a tertiary care hospital in Kolkata. Asian J Pharm Clin Res 2015;8:37-40.

14. Tamizhazhagan V, Ashok K, Rrajesh S. Studies on bacterial population in intensive care unit of thanjavur medical college. Int J Curr Pharm Res 2014;6:55-7.

\section{How to cite this article}

- Shyama K, Prudence AR. Improving antibiotic prescribing pattern and assessment of Co-morbidities associated with respiratory tract infections. Int $\mathrm{J}$ Pharm Pharm Sci 2017;9(2):283-286. 